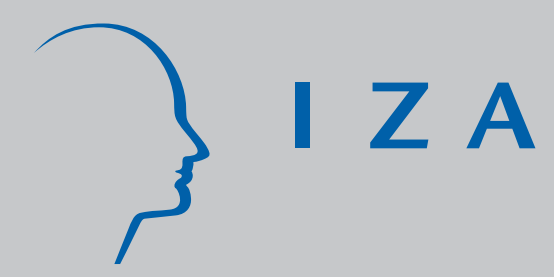

IZADP No. 2105

Unemployment Accounts and Employment Incentives

Alessio J. G. Brown

J. Michael Orszag

Dennis J. Snower

April 2006 


\title{
Unemployment Accounts and Employment Incentives
}

\author{
Alessio J. G. Brown \\ Kiel Institute for World Economics \\ and University of Kiel \\ J. Michael Orszag \\ Watson Wyatt Worldwide \\ and IZA Bonn \\ Dennis J. Snower \\ Kiel Institute for World Economics, \\ University of Kiel, CEPR and IZA Bonn
}

\author{
Discussion Paper No. 2105 \\ April 2006
}

\author{
IZA \\ P.O. Box 7240 \\ 53072 Bonn \\ Germany \\ Phone: +49-228-3894-0 \\ Fax: +49-228-3894-180 \\ Email: iza@iza.org
}

\begin{abstract}
Any opinions expressed here are those of the author(s) and not those of the institute. Research disseminated by IZA may include views on policy, but the institute itself takes no institutional policy positions.
\end{abstract}

The Institute for the Study of Labor (IZA) in Bonn is a local and virtual international research center and a place of communication between science, politics and business. IZA is an independent nonprofit company supported by Deutsche Post World Net. The center is associated with the University of Bonn and offers a stimulating research environment through its research networks, research support, and visitors and doctoral programs. IZA engages in (i) original and internationally competitive research in all fields of labor economics, (ii) development of policy concepts, and (iii) dissemination of research results and concepts to the interested public.

IZA Discussion Papers often represent preliminary work and are circulated to encourage discussion. Citation of such a paper should account for its provisional character. A revised version may be available directly from the author. 
IZA Discussion Paper No. 2105

April 2006

\section{ABSTRACT}

\section{Unemployment Accounts and Employment Incentives}

We explore the far-reaching implications of replacing current unemployment benefit (UB) systems by an unemployment accounts (UA) system. Under the UA system, employed people are required to make ongoing contributions to their UAs and the balances in these accounts are available to them during periods of unemployment. The government is able to undertake balanced-budget interpersonal redistributions among the UAs. At the end of their working lives, people could transfer the remaining balances on their UAs into their pensions. We present an analytical framework to analyse the incentive effects of UAs and calibrate our model for the high unemployment countries of Europe. Our results suggest that this policy reform would significantly change people's employment incentives and could achieve reductions in unemployment without reducing the level of support to the unemployed.

JEL Classification: $\quad 138, \mathrm{~J} 22, \mathrm{~J} 32, \mathrm{J38}, \mathrm{J} 64, \mathrm{~J} 65, \mathrm{~J} 68$

Keywords: unemployment benefits, unemployment accounts, redistribution, employment, unemployment

Corresponding author:

Dennis Snower

The Kiel Institute for the World Economy

Düsternbrooker Weg 120

24105 Kiel

Germany

Email: dennis.snower@ifw-kiel.de 


\section{Introduction}

This paper explores the implications of reforming labor market policy to replace the unemployment benefit (UB) system, in which the unemployed receive benefits that are financed through taxes on the employed, with an unemployment accounts (UA) system. Under unemployment accounts, people have individual unemployment accounts, to which they make ongoing contributions when they are employed. The balances in these accounts are then drawn upon during periods of unemployment. These withdrawals from UAs substitute for unemployment benefits. UAs are hence compulsory saving to provide security against the income loss of unemployment. A UA system need not, and in our view should not, remove redistribution and equity as design considerations. To achieve its equity objectives in a UA system, the government can make balanced-budget interpersonal redistributions among the UAs, taxing the accounts of higher-income people and subsidising those of lower-income people. At the end of their working lives, people could transfer the remaining balances on their UAs into the pension accounts.

The same principle can equally well be applied to incapacity benefits: Current incapacity benefits could be transformed into incapacity accounts. People could draw on these accounts while they are incapacitated and, when they retire, use the remaining balances to top up their pensions.

This paper presents a simple model of how switching from the UB to the UA system would affect people's incentives to work and search for jobs. We then calibrate this model for the high-unemployment countries of Europe and examine the employment and welfare implications of the switch.

In practice, the UA system would run along the following general lines. ${ }^{1}$ Each employed worker contributes a fixed mandatory minimum amount to his or her account each month. Voluntary contributions in excess of the minimum amount are allowed. Upon becoming unemployed an individual is entitled to withdraw a predetermined maximum amount per month. Smaller withdrawals are also allowed.

When a person's account balance is zero, the person is entitled to unemployment assistance, on the same terms and conditions as under the current UB system. In addition, as noted, the government can subsidise the contributions of low-income people. Both these expenditures are financed by taxing contributions of other unemployment account holders. When people's UA balances are sufficiently high, they can use the surplus funds for other purposes; and, as noted, when they retire, their remaining UA balances can be used to top up their pensions. ${ }^{2}$

The UA system can be run on a pay-as-you-go (PAYG) or fully funded basis. ${ }^{3}$ If the UA system is fully funded, then the contribution rates can be set in an actuarially

\footnotetext{
${ }^{1}$ In the model below, we simplify several aspects of this account for the sake of analytical simplicity and transparency.

${ }^{2}$ An unemployed person could also be permitted to use a portion of his UA balance to provide employment vouchers to employers who employ him. See Orszag and Snower (2000).

${ }^{3}$ This aspect is potentially important, for a standard criticism of personalized accounts in other areas of the welfare state (such as pensions, health care, or education) is that they are typically viewed as fully funded systems, and most OECD countries appear to lack the political will to embark on a quick transition to such systems from the current PAYG systems.
} 
fair manner so that, for all the UAs of a particular age cohort in the economy, the discounted value of aggregate minimum benefits is equal to the discounted value of aggregate contributions. ${ }^{4}$ If the UA system is run on a PAYG basis, cross-subsidisation of accounts would also extend across generations. In particular, a part of the UA balances of young people then finances the withdrawals of older people.

Since the UA system is compatible with both PAYG and fully funded schemes, the transition from the former to the latter can proceed at any pace desirable. The closer the system is to being fully funded, the more discretion people can be given in determining who is to manage their UAs, the government or private sector financial institutions. The investment activity of the latter institutions would of course have to be regulated so as to protect individuals.

While UAs are in principle savings accounts, they involve two main advantages over the laissez-faire stance of simply letting people save whatever they want to protect themselves from the income loss of unemployment. First, UAs with mandatory contributions mitigate the moral hazard problem, namely, that individuals - knowing that the government will support them in unemployment regardless of how much they have saved - will have insufficient incentive to save enough. ${ }^{5}$ And second, the UA system also fulfills a redistributive function, whereby people who are unable to support themselves out of their savings receive support from others.

Intuitively, the case for switching from the UB to the UA system is straightforward. Current UB systems, broadly speaking, provide unemployment benefits under the condition that the recipients are unemployed and benefits are financed through taxes falling primarily on the employed. When unemployed people find jobs, their benefits generally are withdrawn (in whole or in part) and taxes are imposed. In effect, under an UB system, people are rewarded for being unemployed (through unemployment benefits) and penalised for being employed (through taxes). The UB system thereby creates an externality, distorting the incentives to work and save, since the unemployed impose costs on the employed.

The unemployed do not take the full social costs of their unemployment into account when seeking jobs. In this way, the UB system depresses job search and thereby stimulates unemployment. Furthermore, the employed do not receive full compensation for the social benefits from their employment and thus, if the relevant substitution effect dominates the income effect, they will work less hard than they otherwise would have. Thereby, the UB system may depress productivity and thereby reduce employment.

Not all of the unemployment benefits and taxes under the UB system are interpersonal redistributions. On the contrary, most of the people who are unemployed at one point in time are employed at other times, and thus part of the taxes they pay when they are employed serve to pay the benefits when they are unemployed, i.e. they are in effect paying themselves. This is an "intrapersonal" redistribution in the form of

\footnotetext{
${ }^{4}$ This method could ensure that generational accounts are in balance. But since some of the UA balances of higher-income individuals would be used to subsidize the contributions of low-income individuals and finance unemployment assistance, the contribution rates would not be actuarially fair for each individual.

${ }^{5}$ Along the same line, maximum withdrawal rates avoid excessive withdrawals.
} 
intertemporal income smoothing, rather than an interpersonal redistribution. These intrapersonal redistributions are handled inefficiently under the UB system, since both the taxes and the benefits create externalities that promote unemployment.

The UA system alleviates these externality problems. For when an unemployed person makes withdrawals from his UA, he is thereby diminishing the amount of funds that are available to him later on. Thus, in comparison to the UB system, the unemployed internalise more of the social costs of their unemployment and thus have greater incentives to search for jobs. When an employed person makes contributions to her UA, she is thereby increasing the account balance that she can draw on in the future. Hence, employed people internalise more of the social benefit of their employment than under the UB system and thus have greater incentives to work.

Of course the interpersonal redistributions in the UA system do create externalities that generate disincentives for job search and for work. But these disincentives are lower than in the UA system than in the UB system. The reason is that the UA system redistributes income more efficiently: Since intrapersonal redistributions are conducted through the UAs rather than through taxes, the costs and benefits of these redistributions are internalized by the account holder, whereas under the UB systen an employed person whose taxes pay for her subsequent unemployment benefits does not internalize the costs and benefits. These taxes discourage work effort and these unemployment benefits discourage job search under UBs, whereas the corresponding intrapersonal redistributions under UAs do not. Hence, UAs generates less unemployment and thus there is less need for interpersonal redistributions.

In short, under the UA system the intrapersonal redistributions lead to lower interpersonal redistributions and thereby to higher employment, lower unemployment and higher productivity without making the unemployed worse off. We will take a first step towards quantifying these effects below.

This paper provides an analytical framework for assessing the labor market implications of switching from the UB to the UA system. The paper is organised as follows. Section 2 depicts these systems in the context of a simple overlappinggenerations model and derives the incentives for job search and work. Section 3 presents a specific analytical form of this model, which is calibrated in Section 4 for European high-unemployment countries. The calibration is used to derive how the switch from the UB to the UA system affects unemployment and welfare. Section 5 concludes.

\section{The General Model}

Workers in our model live for two periods: in the first period the worker is "young", in the second period she is "old". The worker's possible labor market states are illustrated in Figure 1. Upon entering the workforce, each worker faces a predetermined probability $h_{e}$ of becoming employed and a probability $\left(1-h_{e}\right)$ of remaining unemployed. Let $V(y, n)$ and $V(y, u)$ be the discounted lifetime utilities of an employed and unemployed young worker, respectively. Then the discounted lifetime utility of an entrant $(e)$ to the workforce is: 


$$
V(e)=h_{e} V(y, n)+\left(1-h_{e}\right) V(y, u)
$$

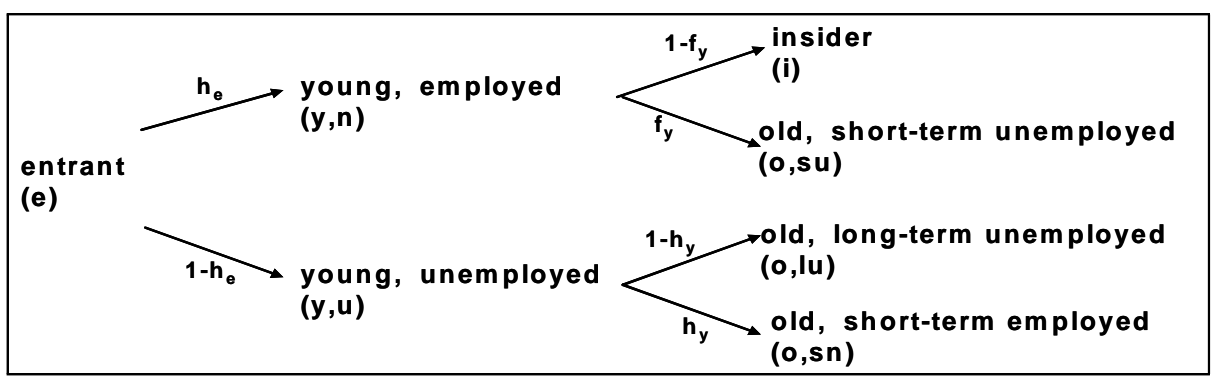

Figure 1: Structure of the Model

A young, employed worker $(y, n)$ faces a probability $f_{y}$ of being fired at beginning of the second period, in which case he turns into an old, short-term unemployed $(o, s u)$ worker. With probability $\left(1-f_{y}\right)$ he is retained in the second period, in which case he and turns into an insider $(i)$, i.e. an employed incumbent worker.

Finally, a young, unemployed worker $(y, u)$ faces a probability $h_{y}$ of being hired at the beginning of the second period, whereupon he becomes an old, short-term employed worker $(o, s n)$. With probability $\left(1-h_{y}\right)$ the young, unemployed $(y, u)$ does not find a job in the second period and becomes an old, long-term unemployed worker $(o, l u)$.

Thus, the unemployment rate of young workers is

$$
u_{y}=\left(1-h_{e}\right)
$$

and the unemployment rate of old workers is

$$
u_{o}=\left(1-h_{e}\right)\left(1-h_{y}\right)+h_{e} f_{y} .
$$

For simplicity, we define the categories "young" and "old" so that both generations are of equal size and the overall unemployment rate is $u=\frac{1}{2}\left(u_{y}+u_{o}\right)$.

Unemployed workers divide their time between leisure and job search; employed workers divide their time between on-the-job leisure (e.g. shirking) and work. The hiring rates in our model depend on search intensity (i.e. the length of time unemployed workers spent searching), and the firing rates depend on work effort (i.e. the length of time spent working), which determines the worker's productivity. Workers make their leisure and consumption decisions so as to maximise their discounted lifetime utilities, taking into account the effects of their leisure choices on the hiring and firing rates. ${ }^{6}$

For simplicity, entrants are assumed to devote all their time to job search, and thus the entrants' hiring rate $h_{e}$ may be taken as an exogenously given constant. All

\footnotetext{
${ }^{6}$ The model is a simple two-period variant of the labor market model developed by Phelps (1994). Our innovations include the incorporation of job search and the analysis of unemployment accounts in this setting.
} 
old workers are assumed to exert a given, fixed level of effort, since they maintain their current (un)employment state and die in the following period. Thus search and work incentives in our model can be assessed simply by examining the leisure and consumption decisions of young workers.

Workers are assumed to have access to capital markets, so that they are able to save their current income or borrow against their future incomes at the market interest rate. This assumption is of particular interest in our context, since it allows us to explore the degree to which savings are a substitute for unemployment accounts. By assuming perfect capital markets, we bias our model against unemployment accounts. With imperfect capital markets, unemployment accounts would increase economic efficiency, at least with voluntary contribution levels, by providing households with a channel for transferring purchasing power through time.

\subsection{Job Search and Work Effort Decisions}

As noted, the hiring rate $h_{y}$ for young unemployed workers $(y, u)$ depends inversely on their leisure $l_{y, u}$ : the more leisure they consume, the less time they spend on job search and thus the fewer jobs they are likely to find. The firing rate $f_{y}$ for young, employed workers $(y, n)$ depends positively on their leisure $l_{y, n}$ : workers who shirk (indulge in more leisure) when young are less likely to be productive when old because of "learning by doing", and thus, more likely to be fired by the firm. (The microfoundations of the hiring and firing functions are presented in appendix A.1.)

A young, employed worker $(y, n)$ has the period utility $v\left(c_{y, n}, l_{y, n}\right)$, where $c_{y, n}$ is consumption and $l_{y, n}$ is the worker's leisure. In the second time period, he receives an old, short-term unemployed worker's utility $V(o, s u)$ with probability $f_{y}\left(l_{y, n}\right)$, and an insider's utility $V(i)$ with probability $\left(1-f_{y}\left(l_{y, n}\right)\right)$. Since the leisure of the old worker is fixed and the young worker transfers unconsumed income into the second period, $V(i)$ and $V(o, s u)$ are determined by the young worker's consumption decision.

The young, employed worker maximises the present value of utility over leisure $l_{y, n}$ and consumption $c_{y, n}$ :

$$
V(y, n)=\max _{l_{y, n}, c_{y, n}}\left[v\left(c_{y, n}, l_{y, n}\right)+\beta\left(f_{y}\left(l_{y, n}\right) V(o, s u)+\left(1-f_{y}\left(l_{y, n}\right)\right) V(i)\right)\right]
$$

where $\beta$ is the discount factor. The first-order conditions for this decision problem are:

$$
\begin{aligned}
& v_{l_{y, n}}=\beta f_{l_{y, n}}[V(i)-V(o, s u)] \\
& v_{c_{y, n}}=-\beta\left[f_{y}\left(l_{y, n}\right) \frac{d V(o, s u)}{d c_{y, n}}+\left(1-f_{y}\left(l_{y, n}\right)\right) \frac{d V(i)}{d c_{y, n}}\right]
\end{aligned}
$$

In other words, the marginal utility of leisure must be set equal to the discounted marginal firing propensity $\left(\beta f_{l_{y, n}}\right)$ times the reward for keeping a job $([V(i)-V(o, s u)])$. Given diminishing marginal utility of leisure, the optimal leisure depends inversely on 
the reward for keeping a job. ${ }^{7}$ Furthermore, the marginal utility of consumption when young $\left(v_{c_{y, n}}\right)$ must be equal to the discounted marginal disutility of not consuming when old, which is a weighted average of the consumption sacrificed when being an old, short-term unemployed worker $\left(\frac{d V(o, s u)}{d c_{y, n}}\right)$ and when being an insider $\left(\frac{d V(i)}{d c_{y, n}}\right)$. The weights are given by the respective probabilities of being fired $\left(f_{y}\left(l_{y, n}\right)\right)$ and being retained $\left(\left(1-f_{y}\left(l_{y, n}\right)\right)\right)$.

Along similar lines, a young, unemployed worker has a period utility $v\left(c_{y, u}, l_{y, u}\right)$, where $c_{y, u}$ is the worker's consumption and $l_{y, u}$ his leisure. In the second time period, she receives the utility of an old, short-term employed worker $V(o, s n)$ with probability $h_{y}\left(l_{y, u}\right)$, and the utility of an old, long-term unemployed worker $V(o, l u)$ with probability $\left(1-h_{y}\left(l_{y, u}\right)\right)$. As above, $V(o, s n)$ and $V(o, l u)$ are fixed by the young worker's consumption decision.

Thus, the young, unemployed worker's decision problem is to find the level of leisure $l_{y, u}$ and consumption $c_{y, u}$ that maximises the present value of utility:

$$
V(y, u)=\max _{l_{y, u}, c_{y, u}}\left[v\left(c_{y, u}, l_{y, u}\right)+\beta\left(h_{y}\left(l_{y, u}\right) V(o, s n)+\left(1-h_{y}\left(l_{y, u}\right)\right) V(o, l u)\right)\right]
$$

The first-order conditions for this problem are:

$$
\begin{aligned}
& v_{l_{y, u}}=-\beta h_{l_{y, u}}[V(o, s n)-V(o, l u)] \\
& v_{c_{y, u}}=\beta\left[h_{y}\left(l_{y, u}\right) \frac{d V(o, s n)}{d c_{y, u}}+\left(1-h_{y}\left(l_{y, u}\right)\right) \frac{d V(o, l u)}{d c_{y, u}}\right]
\end{aligned}
$$

Here, the marginal utility of leisure must be set equal to the discounted marginal hiring propensity $\left(-\beta h_{l_{y, u}}\right)$ times the reward for seeking a job $([V(o, s n)-V(o, l u)])$. As above, diminishing marginal utility of leisure implies that the optimal level of leisure depends inversely on the reward for seeking a job. ${ }^{8}$ Accordingly, the marginal utility of consumption when young $\left(v_{c_{y, u}}\right)$ must be equal to the discounted marginal disutility of not consuming when old, which is a weighted average of the consumption sacrificed when being an old, short-term employed worker $\left(\frac{d V(o, s n)}{d c_{y, u}}\right)$ and when being an old, long-term unemployed worker $\left(\frac{d V(o, l u)}{d c_{y, u}}\right)$. Here the weights are given by the respective probabilities of being hired $\left(h_{y}\left(l_{y, u}\right)\right)$ and remaining unemployed $\left(\left(1-h_{y}\left(l_{y, u}\right)\right)\right)$

An attractive feature of this model is that both job search and work effort are determined by the difference between the value of being employed and that of being unemployed (by the first-order conditions for leisure (eq. 5 and 8)). Below, we will show how the UB and UA systems have different effects on this difference, which will help explain why the two systems have different unemployment and welfare outcomes.

\footnotetext{
${ }^{7}$ This is true if (as assumed below) leisure and consumption are complements or weak substitutes. If they were sufficiently strong substitutes, then the decrease in period one consumption might lead to a sufficient increase in the marginal utility of leisure to counterbalance the effect on leisure from the reward for remaining employed.

${ }^{8} \mathrm{As}$ in the previous footnote, this is true if (as assumed below) leisure and consumption are complements or weak substitutes.
} 


\subsection{The Unemployment Benefit (UB) System}

In an unemployment benefit system each unemployed worker receives an exogenously given real unemployment benefit $b$, and unemployment benefits are financed through a payroll tax, where $\tau$ is the payroll tax rate. For simplicity, all employed workers are assumed to receive the same, exogenously given wage $w$, normalised to unity. ${ }^{9}$

The government is in balance in each time period, i.e. the government's expenditures on unemployment benefits are equal to its tax receipts. Specifically, the value of unemployment benefits received by the unemployed workers (young, unemployed workers $(y, u)$, old, long-term unemployed workers $(o, l u)$, and old, short-term unemployed workers $(o, s u)$ ) must be equal to the value of taxes paid by the employed workers (young, employed workers $(y, n)$, insiders $(i)$, and old, short-term employed workers $(o, s n))$ in each period: ${ }^{10}$

$$
\begin{aligned}
& b\left(\left(1-h_{e}\right)+\left(1-h_{e}\right)\left(1-h_{y}\left(l_{y, u}\right)\right)+h_{e} f_{y}\left(l_{y, n}\right)\right) \\
= & w \tau\left(h_{e}+h_{e}\left(1-f_{y}\left(l_{y, n}\right)\right)+\left(1-h_{e}\right) h_{y}\left(l_{y, u}\right)\right)
\end{aligned}
$$

which can be rewritten as

$$
\nu u=\tau(1-u)
$$

with the unemployment rate $u$ determined by eq. 2 and 3 and with the replacement ratio $^{11} \nu=\frac{b}{w}$. Thus, the payroll tax rate under the UB system is:

$$
\tau=\frac{\nu u}{(1-u)}=\frac{\nu\left(\left(1-h_{e}\right)+\left(1-h_{e}\right)\left(1-h_{y}\left(l_{y, u}\right)\right)+h_{e} f_{y}\left(l_{y, n}\right)\right)}{\left(h_{e}+h_{e}\left(1-f_{y}\left(l_{y, n}\right)\right)+\left(1-h_{e}\right) h_{y}\left(l_{y, u}\right)\right)}
$$

By eq. 12, the payroll tax level is increasing in both the leisure of the employed and unemployed.

\subsection{The Unemployment Accounts (UA) System}

Under the UA system unemployed workers are assumed to receive a payment equal to the unemployment benefit $b$ out of their UA. ${ }^{12}$ This enables us to compare the incentives under both systems when the unemployed receive identical support. Thus, for a real interest rate $r$, the contribution of a young, employed worker to her UA must be $\frac{b}{1+r}$.

The payroll tax rate $\kappa$ must be set so that total tax receipts by young and old employed workers are equal total expenditures on unemployment benefits. In contrast

\footnotetext{
${ }^{9} \mathrm{By}$ implication, we do not investigate the general equilibrium effects of the shift from the UB to the UA system that operate via the wage.

${ }^{10}$ Since our analysis focuses on the stationary steady state, this is of course equivalent to the condition that the present value of government expenditures is equal to the present value of government tax receipts. An equivalent formulation is that the deficit (surplus) generated by the young generation must be equal to the surplus (deficit) generated by the old generation.

${ }^{11}$ Naturally, since we have normalized the wage to unity, the replacement ratio $\nu$ is equal to the unemployment benefit $b$ in our analysis. We nevertheless distinguish between these parameters to aid the reader's intuition.

${ }^{12}$ This payment is financed either $(a)$ by past forced savings or (if the account balances are insufficient to provide the payment $(b)$ by government transfers.
} 
to the UB system old, short-term unemployed workers $(o, s u)$ finance their own unemployment using their accounts. ${ }^{13}$ Thus, payments of $b$ must be financed via taxes only for young, unemployed workers $(y, u)$ and the old, long-term unemployed workers $(o, l u)$, who have no balances on their accounts. The balanced budget constraint is:

$$
\begin{aligned}
& b\left(\left(1-h_{e}\right)+\left(1-h_{e}\right)\left(1-h_{y}\left(l_{y, u}\right)\right)\right) \\
= & \kappa w\left(h_{e}+h_{e}\left(1-f_{y}\left(l_{y, n}\right)\right)+\left(1-h_{e}\right) h_{y}\left(l_{y, u}\right)\right)
\end{aligned}
$$

which can be rewritten as

$$
\nu\left(u-\frac{1}{2} h_{e} f_{y}\left(l_{y, n}\right)\right)=\kappa(1-u)
$$

with the unemployment rate $u$ determined by eq. 2 and 3 and with the replacement ratio $\nu=\frac{b}{w}$. Hence the tax rate is

$$
\kappa=\nu \frac{\left(u-\frac{1}{2} h_{e} f_{y}\left(l_{y, n}\right)\right)}{(1-u)}=\nu \frac{\left(1-h_{e}\right)+\left(1-h_{e}\right)\left(1-h_{y}\left(l_{y, u}\right)\right)}{h_{e}+h_{e}\left(1-f_{y}\left(l_{y, n}\right)\right)+\left(1-h_{e}\right) h_{y}\left(l_{y, u}\right)}
$$

Comparing the tax rates under the UB system (eq. 12) and UA system (eq. 16), it is clear that, for any given unemployment rate, the tax rate is lower under the UA system than under the UB system.

We now proceed to analyse how the job search and work effort decisions are affected by these UB and UA systems.

\subsection{Comparison of Employment Incentives}

As we have seen in the first-order conditions for leisure (eq. 5 and 8), the leisure decisions depend negatively on the reward for keeping a job, which is the reward for work effort, and the reward for seeking a job, namely the reward for search effort. Thus, to understand why the UB and UA systems generate different employment incentives, it is useful to consider what workers stand to lose from being unemployed under the two systems.

Table 1 compares the two systems by describing old workers' consumption as a function of the worker's labour market history and also presents the associated rewards for keeping a job $\left(\Delta_{n}\right)$ and seeking a job $\left(\Delta_{u}\right)$. In what follows, the superscript " $B$ " stands for the unemployment "benefit" system and the superscript " $A$ " for the unemployment "accounts" system.

As noted above, workers are assumed to have access to capital markets and $s$ is the purchasing power transfered through saving into the second period by young workers, which earns interest at the interest rate $r .{ }^{14}$ This saving may be described as "voluntary", in the sense that it is the outcome of the the workers' optimisation

\footnotetext{
${ }^{13}$ To achieve better comparability to the UB system instead of taxing the contributions to the accounts, we simply tax the wage. Levying taxes just in the first period - on the contributions to the accounts - leads to the same qualitative results.

${ }^{14}$ As above, the subscript " $n$ " refers to the employment state and " $u$ " to the unemployment state.
} 


\begin{tabular}{|c|c|c|c|}
\hline \multicolumn{4}{|c|}{ The Unemployment Benefit (UB) System } \\
\hline & Employed, when old & Unemployed, when old & Reward $\Delta^{B}$ \\
\hline Employed, when young & $w(1-\tau)+s_{n}^{B}(1+r)$ & $b+s_{n}^{B}(1+r)$ & $\Delta_{n}^{B}=w(1-\tau)-b$ \\
\hline Unemployed, when young & $w(1-\tau)+s_{u}^{B}(1+r)$ & $b+s_{u}^{B}(1+r)$ & $\Delta_{u}^{B}=w(1-\tau)-b$ \\
\hline \multicolumn{4}{|c|}{ The Unemployment Accounts (UA) System } \\
\hline & Employed, when old & Unemployed, when old & Reward $\Delta^{A}$ \\
\hline Employed, when young & $w(1-\kappa)+b+s_{n}^{A}(1+r)$ & $b+s_{n}^{A}(1+r)$ & $\Delta_{n}^{A}=w(1-\kappa)$ \\
\hline Unemployed, when young & $w(1-\kappa)+s_{u}^{A}(1+r)$ & $b+s_{u}^{A}(1+r)$ & $\Delta_{u}^{A}=w(1-\kappa)-b$ \\
\hline
\end{tabular}

Table 1: Old workers' consumption and the associated rewards for keeping a job $\left(\Delta_{n}\right)$ and seeking a job $\left(\Delta_{u}\right)$ as a function of their past and current employment states.

decisions under the prevailing institutional setting (UB or UA); it may be contrasted with the "forced saving" in the form of contributions to the UAs. As our workers live only two periods, in the second period they withdraw their total savings.

Under the UB system old workers receive $w(1-\tau)$ plus their savings when employed and $b$ plus their savings when unemployed; thus they stand to loose $\Delta^{B}=$ $w(1-\tau)-b$ from being unemployed, regardless of whether they were employed or unemployed when they were young. Thus, in the UB system the reward for keeping a job $\left(\Delta_{n}^{B}\right)$ is equal to the reward for seeking a job $\left(\Delta_{u}^{B}\right)$.

Under the UA system, by contrast, the respective rewards $\left(\Delta_{n}^{A}\right.$ and $\left.\Delta_{u}^{A}\right)$ are not equal, and hence, the incentives are different - especially for young, employed workers. If they continue to be employed, they receive $w(1-\kappa)$ and the sum of their savings, namely their interest-bearing voluntary savings $s_{n}^{A}(1+r)$ and forced savings $b$ from the UAs. If they become unemployed, they still receive in addition to their voluntary savings $s_{n}^{A}(1+r)$, their forced savings $b$ from the accounts. Hence, in contrast to the UB system, the reward for keeping a job is $\Delta_{n}^{A}=w(1-\kappa)$.

As for old, short-term employed workers, they receive $w(1-\kappa)$ plus their interestbearing savings $s_{u}^{A}(1+r)$ and old, long-term unemployed workers recieve $b$ plus their interest-bearing savings $s_{u}^{A}(1+r)$. Now the resulting difference, the reward for seeking a job, is $\Delta_{u}^{A}=w(1-\kappa)-b$.

In sum, in the UA system workers stand to loose more from being unemployed: the rewards for keeping and seeking a job in consumption terms are higher, particularly the former, which is the reward for work effort to young, employed workers. Under an UA system, these workers will not benefit from becoming unemployed (through the payment of unemployment benefits), in contrast to the UB system. The reason is, that under the UA system these workers are forced to redistribute their income intrapersonally via their UAs. By financing their own possible future unemployment fully themselves via their accounts, these workers completely internalise the cost of their own unemployment and hence stand to loose more from being unemployed than 
under the UB system. ${ }^{15}$ We call this the internalisation effect.

As the leisure decision depends negatively on the reward for keeping a job, the higher reward for keeping a job with UAs induces young, employed workers to increase their work effort (take less leisure at work). Consequently firing rates will fall and unemployment of old workers will be lower.

Additionally, under the UA system young, employed workers stand to loose more from being unemployed when old $\left(\Delta_{n}^{A}=w(1-\kappa)\right)$ than workers who were unemployed when young under the UA system and thus did not contribute to their UAs $\left(\Delta_{u}^{A}=\right.$ $w(1-\kappa)-b)$. Due to the internalisation effect under the UA system, the employment incentives depend on workers' labour market history.

Since young, employed workers under the UA system save for their own unemployment, taxes are only required to finance unemployment assistance for young, unemployed workers and long-term unemployed workers. The cost of unemployment of old, short-term unemployed workers is not imposed on others. Consequently the tax rate is lower under the UA system than under the UB system (as indicated by eqs. 12 and 16). Lower taxes mean that workers receive higher rewards for keeping a job and seeking a job. We call this the tax reduction effect.

Hence, the tax reduction effect not only raises the reward for keeping a job under the UA system relative to the UB system, it also generates a higher reward for seeking a job. Thus, young, unemployed workers have an incentive to search harder for jobs (take less leisure while unemployed $)^{16}$ and, since hiring rates depend positively on search intensity, hiring rates will rise.

To be precise, there are in fact two tax reduction effects in our model. In addition to the direct tax reduction effect above (whereby young, employed workers finance their own unemployment support rather than receiving unemployment benefits financed through taxes), there is also an indirect tax reduction effect: The increased employment broadens the tax base and the lower unemployment implies that there are fewer unemployed workers with insufficient UA balances to support themselves. Accordingly, the tax rate that is required in the UA system to finance the unemployment support is even lower. (This in turn improves the incentives for job search and work effort even further, leading to another round of unemployment reductions, and so on.)

Summing up, firing rates are lower and hiring rates are higher under the UA system than under the UB system and thus (by eqs. 2 and 3) unemployment is lower under the UA system.

In the following section we consider specific functional forms for the behavioral relations above and derive the optimal search and work effort decisions for the UB

\footnotetext{
${ }^{15}$ In utility terms for any concave utility function this result depends on the respective size of the "voluntary" savings in both systems. For any concave utility function this result holds under the reasonable parameter values in our calibration and under the assumption that $s_{n}^{A}(1+r)+b>$ $s_{n}^{B}(1+r)>s_{n}^{A}(1+r)$. Then the reward for keeping a job in utility terms $\Lambda_{n}$ is greater under the UA than the UB system: $\Lambda_{n}^{A}=v\left(w(1-\kappa)+s_{n}^{A}(1+r)+b\right)-v\left(s_{n}^{A}(1+r)+b\right)>\Lambda_{n}^{B}=$ $v\left(w(1-\tau)+s_{n}^{B}(1+r)\right)-v\left(b+s_{n}^{B}(1+r)\right)$.

${ }^{16}$ Again, the result in utility terms for any concave utility function depends on the size of the savings in the two systems. Under reasonable parameter values in our calibration this result holds: $\Lambda_{u}^{A}=$ $v\left(w(1-\kappa)+s_{u}^{A}(1+r)\right)-v\left(b+s_{u}^{A}(1+r)\right)>\Lambda_{u}^{B}=v\left(w(1-\tau)+s_{u}^{B}(1+r)\right)-v\left(b+s_{u}^{B}(1+r)\right)$.
} 
and UA systems. We then proceed to calibrate the resulting model and evaluate the unemployment and welfare implications of moving from the UB to the UA system.

\section{The Specific Model}

Let the workers' utility function be Cobb-Douglas:

$$
v(c, l)=\frac{\left(c^{\alpha} l^{(1-\alpha)}\right)^{\gamma}}{\gamma}
$$

and let hiring and firing rates be linear (the microfoundations are derived in appendix A.1):

$$
\begin{gathered}
h_{y}\left(l_{y, u}\right)=\theta\left(1-a l_{y, u}\right) \\
f_{y}\left(l_{y, n}\right)=\phi l_{y, n}
\end{gathered}
$$

For these functional forms, we now proceed to examine incentives under the UB and UA systems.

\subsection{The Unemployment Benefit System}

Under the UB system, the optimisation problem of a young, employed worker is: ${ }^{17}$

$$
\begin{aligned}
V^{B}(y, n)= & \max _{l_{y, n}, s_{n}} \frac{1}{\gamma}\left(\left(\left(w(1-\tau)-s_{n}\right)^{\alpha} l_{y, n}^{1-\alpha}\right)^{\gamma}\right) \\
& +\beta\left(\begin{array}{c}
f_{y}\left(l_{y, n}\right) \frac{1}{\gamma}\left(b+s_{n}(1+r)\right)^{\alpha \gamma} \\
+\left(1-f_{y}\left(l_{y, n}\right)\right) \frac{1}{\gamma}\left(\left(w(1-\tau)+s_{n}(1+r)\right)^{\alpha \gamma}\right)
\end{array}\right)
\end{aligned}
$$

subject to ${ }^{18}$

$$
0 \leq l_{y, n} \leq \frac{1}{\phi}
$$

The resulting optimal leisure decision is: ${ }^{19}$

$$
\begin{aligned}
l_{y, n}^{B}= & \left(\frac{\beta \phi}{\gamma(1-\alpha)}\left(\left(w(1-\tau)+s_{n}(1+r)\right)^{\alpha \gamma}-\left(b+s_{n}(1+r)\right)^{\alpha \gamma}\right)\right)^{\frac{1}{(1-\alpha) \gamma-1}} \\
& \left(w(1-\tau)-s_{n}\right)^{-\frac{\alpha \gamma}{(1-\alpha) \gamma-1}}
\end{aligned}
$$

The optimal saving decision is given by the following implicit function: ${ }^{20}$

\footnotetext{
${ }^{17}$ The superscript "B" stands for the Unemployment "Benefit" System.

${ }^{18}$ This condition ensures that the firing rate $f_{y}$ is non-negative and not greater than 1.

${ }^{19}$ We substitute the firing rate, eq. 19, into the optimisation problem, eq. 20 . We focus on interior solutions.

${ }^{20}$ We express consumption as income minus saving and optimize with respect to saving.
} 


$$
\begin{aligned}
0= & \left(w(1-\tau)-s_{n}\right)^{\alpha \gamma-1} l_{y, n}^{(1-\alpha) \gamma} \\
& -(1+r) \beta\left(\begin{array}{c}
f_{y}\left(l_{y, n}\right)\left(b+s_{n}(1+r)\right)^{\alpha \gamma-1} \\
+\left(1-f_{y}\left(l_{y, n}\right)\right)\left(w(1-\tau)+s_{n}(1+r)\right)^{\alpha \gamma-1}
\end{array}\right)
\end{aligned}
$$

The optimisation problem of a young, unemployed worker is:

$$
\begin{aligned}
V^{B}(y, u)= & \max _{l_{y, u}, s_{u}} \frac{1}{\gamma}\left(\left(b-s_{u}\right)^{\alpha} l_{y, u}^{1-\alpha}\right)^{\gamma} \\
& +\beta\left(\begin{array}{c}
h_{y}\left(l_{y, u}\right) \frac{1}{\gamma}\left(\left(w(1-\tau)+s_{u}(1+r)\right)^{\alpha \gamma}\right) \\
+\left(1-h_{y}\left(l_{y, u}\right)\right) \frac{1}{\gamma}\left(\left(b+s_{u}(1+r)\right)^{\alpha \gamma}\right)
\end{array}\right)
\end{aligned}
$$

subject to ${ }^{21}$

$$
\max \left[0, \frac{1}{a}\left(1-\frac{1}{\theta}\right)\right] \leq l_{y, u} \leq \frac{1}{a}
$$

The resulting optimal leisure decision is: ${ }^{22}$

$$
\begin{aligned}
l_{y, u}^{B}= & \left(\frac{\beta \theta a}{\gamma(1-\alpha)}\left(\left(w(1-\tau)+s_{u}^{B}(1+r)\right)^{\alpha \gamma}-\left(b+s_{u}^{B}(1+r)\right)^{\alpha \gamma}\right)\right)^{\frac{1}{(1-\alpha) \gamma-1}} \\
& \left(b-s_{u}^{B}\right)^{-\frac{\alpha \gamma}{(1-\alpha) \gamma-1}}
\end{aligned}
$$

and the following implicit function yields the optimal saving decision:

$$
\begin{aligned}
0= & \left(b-s_{u}\right)^{\alpha \gamma-1} l_{y, u}^{(1-\alpha) \gamma} \\
& -(1+r) \beta\left(\begin{array}{c}
h_{y}\left(l_{y, u}\right)\left(w(1-\tau)+s_{u}(1+r)\right)^{\alpha \gamma-1} \\
+\left(1-h_{y}\left(l_{y, u}\right)\right)\left(b+s_{u}(1+r)\right)^{\alpha \gamma-1}
\end{array}\right)
\end{aligned}
$$

The system of equations 22, 23, 26, 27 and the government budget constraint, eq. 11, describe the equilibrium levels of job search and work effort under the UB system, to be calibrated in the next section.

\subsection{The Unemployment Accounts (UA) System}

Under the accounts system, the young, employed worker's decision problem is to solve the problem ${ }^{23}$

$$
\begin{aligned}
V^{A}(y, n)= & \max _{l_{y, n}, s_{n}} \frac{1}{\gamma}\left(\left(w(1-\kappa)-\frac{b}{1+r}-s_{n}\right)^{\alpha} l_{y, n}^{1-\alpha}\right)^{\gamma} \\
& +\beta\left(\begin{array}{c}
f_{y}\left(l_{y, n}\right) \frac{1}{\gamma}\left(b+s_{n}(1+r)\right)^{\alpha \gamma} \\
+\left(1-f_{y}\left(l_{y, n}\right)\right) \frac{1}{\gamma}\left(\left(w(1-\kappa)+b+s_{n}(1+r)\right)^{\alpha \gamma}\right)
\end{array}\right)
\end{aligned}
$$

\footnotetext{
${ }^{21}$ This condition ensures that the hiring rate $h_{y}$ is non-negative and not greater than 1 .

${ }^{22}$ We substitute the hiring rate, eq. 18, into the optimisation problem, eq. 24.

${ }^{23}$ The superscript " $A$ " stands for the Unemployment "Accounts" System.
} 
subject to the leisure constraint, eq. 21 . The resulting optimal leisure decision is: ${ }^{24}$

$$
\begin{aligned}
l_{y, n}^{A}= & \left(\frac{\beta \phi}{\gamma(1-\alpha)}\left(\left(w(1-\kappa)+b+s_{n}(1+r)\right)^{\alpha \gamma}-\left(b+s_{n}(1+r)\right)^{\alpha \gamma}\right)\right) \\
& \left(w(1-\kappa)-\frac{1}{1+r} b-s_{n}\right)^{-\frac{\alpha \gamma}{(1-\alpha) \gamma-1}}
\end{aligned}
$$

and the optimal saving decision is given by the following implicit function:

$$
\begin{aligned}
0= & \left(w(1-\kappa)-\frac{1}{1+r} b-s_{n}\right)^{\alpha \gamma-1} l_{y, n}^{(1-\alpha) \gamma} \\
& -(1+r) \beta\left(\begin{array}{c}
f_{y}\left(l_{y, n}\right)\left(b+s_{n}(1+r)\right)^{\alpha \gamma-1} \\
+\left(1-f_{y}\left(l_{y, n}\right)\right)\left(w(1-\kappa)+b+s_{n}(1+r)\right)^{\alpha \gamma-1}
\end{array}\right)
\end{aligned}
$$

The young unemployed worker's optimisation problem is:

$$
\begin{aligned}
V^{A}(y, u)= & \max _{l_{y, u}, s_{u}} \frac{1}{\gamma}\left(\left(b-s_{u}\right)^{\alpha} l_{y, u}^{1-\alpha}\right)^{\gamma} \\
& +\beta\left(\begin{array}{c}
h_{y}\left(l_{y, u}\right) \frac{1}{\gamma}\left(\left(w(1-\kappa)+s_{u}(1+r)\right)^{\alpha \gamma}\right) \\
+\left(1-h_{y}\left(l_{y, u}\right)\right) \frac{1}{\gamma}\left(\left(b+s_{u}(1+r)\right)^{\alpha \gamma}\right)
\end{array}\right)
\end{aligned}
$$

subject to the leisure constraint, eq. 25. In this case, the resulting optimal leisure decision is: ${ }^{25}$

$$
\begin{aligned}
l_{y, u}^{A}= & \left(\frac{\beta \phi}{\gamma(1-\alpha)}\left(\left(w(1-\kappa)+s_{u}(1+r)\right)^{\alpha \gamma}-\left(b+s_{u}(1+r)\right)^{\alpha \gamma}\right)\right)^{\frac{1}{(1-\alpha) \gamma-1}} \\
& \left(b-s_{u}\right)^{-\frac{\alpha \gamma}{(1-\alpha) \gamma-1}}
\end{aligned}
$$

and the first-order condition for saving:

$$
\begin{aligned}
0= & \left(b-s_{u}\right)^{\alpha \gamma-1} l_{y, u}^{(1-\alpha) \gamma} \\
& -(1+r) \beta\left(\begin{array}{c}
h_{y}\left(l_{y, u}\right)\left(w(1-\kappa)+s_{u}(1+r)\right)^{\alpha \gamma-1} \\
+\left(1-h_{y}\left(l_{y, u}\right)\right)\left(b+s_{u}(1+r)\right)^{\alpha \gamma-1}
\end{array}\right)
\end{aligned}
$$

Under the UA system the equilibrium levels of job search and work effort are described by the system of Eq. 29, 30, 32, 33 and the government budget constraint, Eq. 15, also to be calibrated in the next section.

\section{Evaluation of Employment Incentives}

\subsection{Calibration}

We now evaluate the incentive effects resulting from a shift from an UB to an UA system. With regard to the high-unemployment countries in Europe, namely Belgium,

\footnotetext{
${ }^{24}$ We substitute the firing rate, eq. 19, into the optimisation problem, eq. 28.

${ }^{25}$ We substitute the hiring rate, eq. 18, into the optimisation problem, eq. 31.
} 
France, Germany, Italy and Spain, our analysis shows, that for reasonable parameter values, the unemployment reductions are substantial.

The period of analysis is one year. The interest rate $r$ is set at $4 \%$ per year, which corresponds to the average real interest rate in the OECD over the last four decades, and we set $\beta=\frac{1}{1+r}$. We let the coefficient of relative risk aversion $\left(\frac{1}{1-\gamma}\right)$ be 4 , and the utility coefficient $\alpha$ be 0.85 .

The parameters of the hiring function $a, \theta$, of the firing function $\phi$ and the hiring rate $h_{e}$ for each country are assigned the values necessary for the model to reproduce the net replacement ratio, the average duration of job tenure, and the unemployment rate of the five high-unemployment countries, as shown in Table 2. These variables are defined as follows: (i) The net replacement ratio ( $\nu^{\text {net }}$, for the current UB systems) is taken to be the after-tax replacement ratio for $2002(\operatorname{OECD}(2004)),{ }^{26}$ so that the unemployment benefit $b$ in our model is given by $b=w \nu^{\text {net }}(1-\tau)$, where $\nu^{\text {net }}=$ $\frac{\nu}{(1-\tau)}$. (ii) The average job tenure (in years) is that for 2002 in Auer et al. (2004), and it is computed as as the inverse of the rate of outflow from employment $1 / f_{y}$ (see appendix A.2). (iii) The unemployment rate is the standardised unemployment rate for 2002 (OECD 2005).

\begin{tabular}{|l|c|c|c|}
\hline & $v^{\text {net }}$ & $1 / f_{y}$ & $u$ \\
\hline Belgium & 68.89 & 11.6 & 7.3 \\
\hline France & 78.39 & 11.2 & 8.9 \\
\hline Germany & 76.50 & 10.7 & 8.2 \\
\hline Italy & 60.22 & 12.1 & 8.6 \\
\hline Spain & 72.44 & 9.9 & 11.3 \\
\hline
\end{tabular}

Table 2: Net replacement ratio (\%), average job tenure (years) and standardised unemployment rate (\%) for 2002.

\subsection{Results}

As noted (section 2.4), the incentive improvement from switching from an UB to an UA system is generated by an internalisation effect (the internalisation of the cost of unemployment increases the reward for keeping a job) and a resulting tax reduction effect (the resulting reduction in the tax rate increases the reward for keeping and seeking a job). For the calibrated model above, the plots in Figure 2 shed light on the relative importance of these two effects, by comparing the rewards for keeping and seeking a job under both systems for varying replacement ratios.

We have seen that the employment incentives under the UB system are indepen-

\footnotetext{
${ }^{26}$ The net replacement ratio is the average of net replacement rates for six family types and different earning levels for the initial phase of unemployment (i.e. upon entering unemployment following any benefit waiting period) for somebody who was previously employed on a full-time basis, 2002.
} 

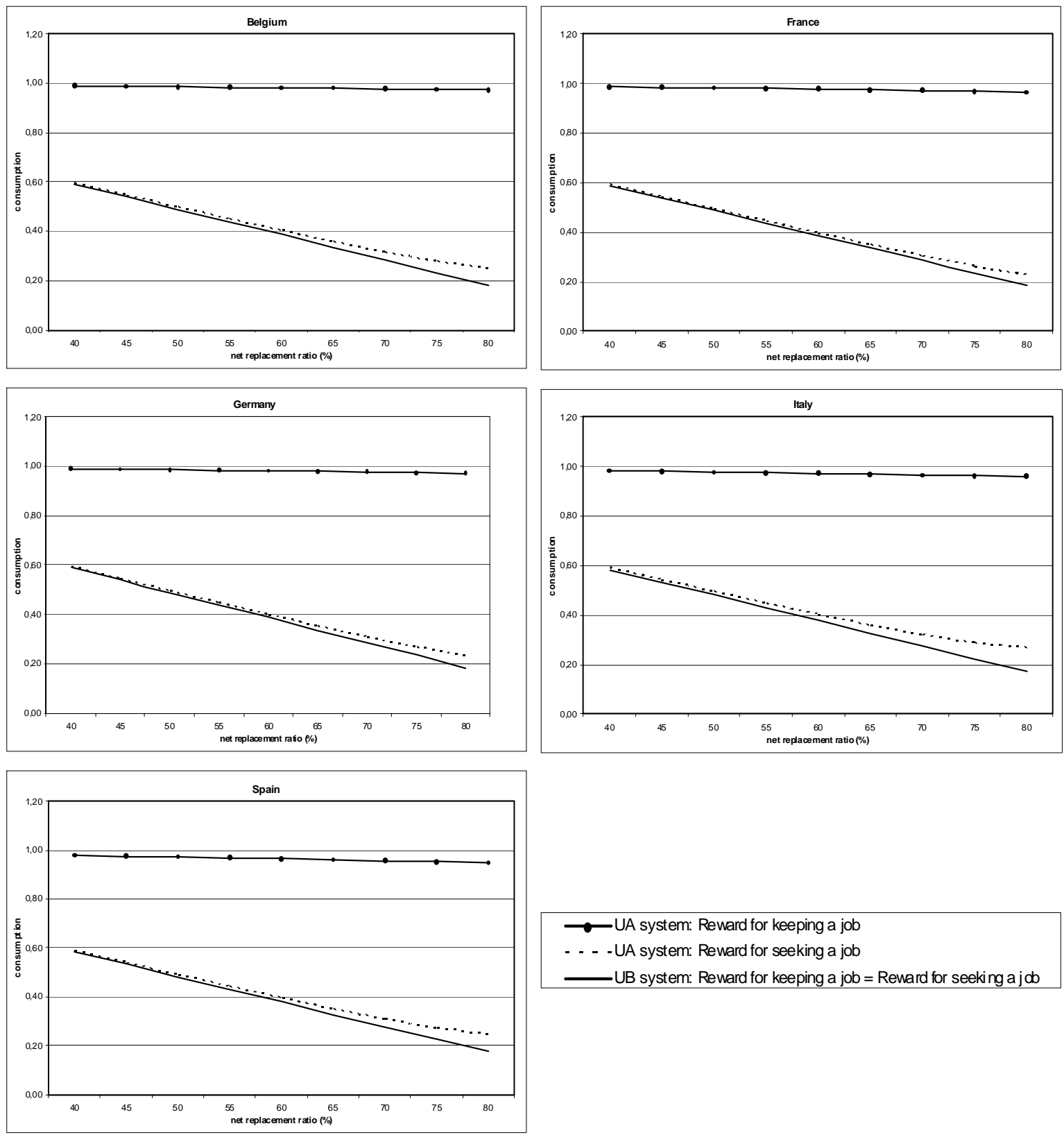

UA system: Reward for keeping a job

- - - - UA system: Reward for seeking a job

UB system: Reward for keeping a job = Reward for seeking a job

Figure 2: The relation between the net replacement ratio and the reward for keeping and seeking a job, in consumption terms, under the UB and the UA system for Belgium, France, Germany, Italy and Spain.

dent of a worker's employment history, i.e. the reward for seeking a job is equal to the reward for keeping a job (as shown in Figure 2). When moving from the UB to the UA system, the reward for keeping a job rises substantially, as indicated in Fig. 2, where this reward is measured in consumption terms. The increased reward - implying increased incentives for work effort - is due to both the internalisation and tax reduction effects. The reward for seeking a job also rises, as shown, but by substantially less, since this change - implying increased job search incentives - is driven only by the tax reduction effect.

Figure 2 also shows that the replacement ratio has a weaker influence on the 
reward for keeping a job under UAs than under UBs. Naturally, the replacement ratio does have some effect under UAs, since the higher replacement ratio implies more interpersonal redistribution to those unemployed workers who are unable to support themselves and thus a correspondingly higher tax rate on the employed workers. But under the UA system, workers internalise more of the cost of their own unemployment (specifically, unemployed workers who were previously employed pay for themselves), and thus the tax rate rises less with the replacement ratio and work incentives are reduced by correspondingly less as well.

Table 3 summarises the implications of these incentive effects from switching to the UA system for unemployment $(u)$ and welfare ${ }^{27}(W)$ for our calibrated model. (The effects are given in terms of percentage changes. $)^{28}$

\begin{tabular}{|l|l|l|}
\hline & $\% d u$ & $\% d W$ \\
\hline Belgium & -47.9 & 24.2 \\
France & -46.3 & 48.4 \\
Germany & -50.9 & 41.1 \\
Italy & -34.4 & 17.4 \\
Spain & -37.7 & 53.5 \\
\hline
\end{tabular}

Table 3: The percentage change in unemployment rates and welfare resulting from a shift from the UB to the UA system.

It is worth emphasising that these substantial reductions in unemployment are achieved even though unemployed people receive the same amount of unemployment support in both systems.

The improved employment incentives depicted in Fig. 2 imply unemployment reductions that are depicted in Fig. 3, which specifically shows how the unemployment reductions are related to the net replacement ratio.

Fig. 4 depicts the tax reductions associated with a switch to the UA system associated with varying replacement ratios. (The greater is the replacement ratio, the greater is the tax rate necessary to finance this replacement ratio under the UA and UB systems.)

The greater is the replacement ratio, the greater is the difference between the externalities generated by the UBs and those generated by the UAs. The reason is that a higher replacement ratio under the UA system means that more support for the unemployed is paid out of the UAs and the greater is the associated internalisation

\footnotetext{
${ }^{27}$ The welfare of the population is calculated as the sum of the weighted utility of workers over both labour market states and both generations, whereby the weights are given by their respective share in the population. See appendix A.3. For expositional convenience, we have included an additive constant in the utility function.

${ }^{28}$ The cross-country rankings of changes in unemployment and welfare do not coincide with the cross-country ranking of the net replacement ratio since these countries differ in terms of variables other than the replacement ratio as well, viz., they also differ in terms of average job tenure and average unemployment rates, implying differences in hiring rates for entrants. Consequently, there are cross-country differences in the hiring and firing functions.
} 


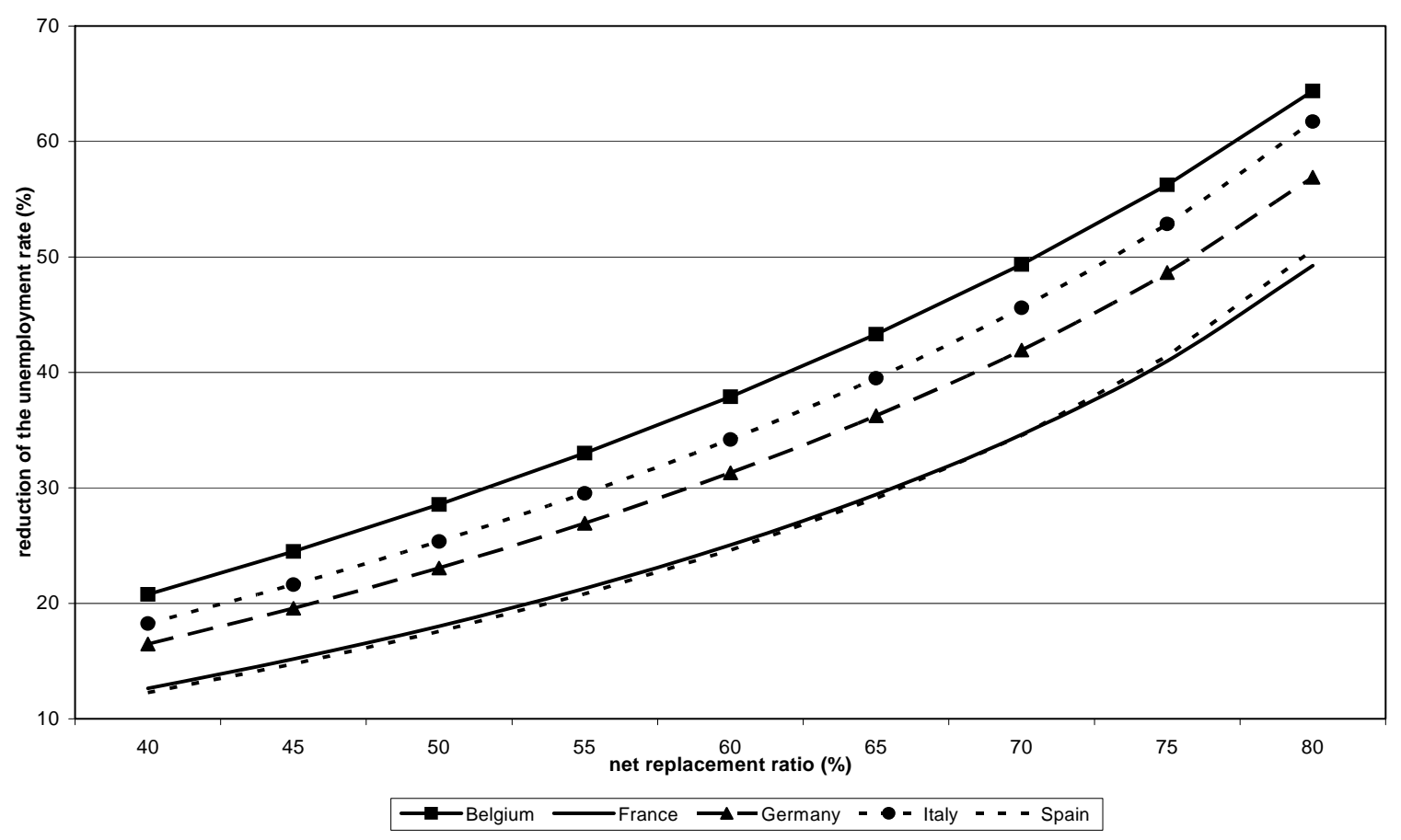

Figure 3: The relation between the net replacement ratio and the percentage reduction of the unemployment rate.

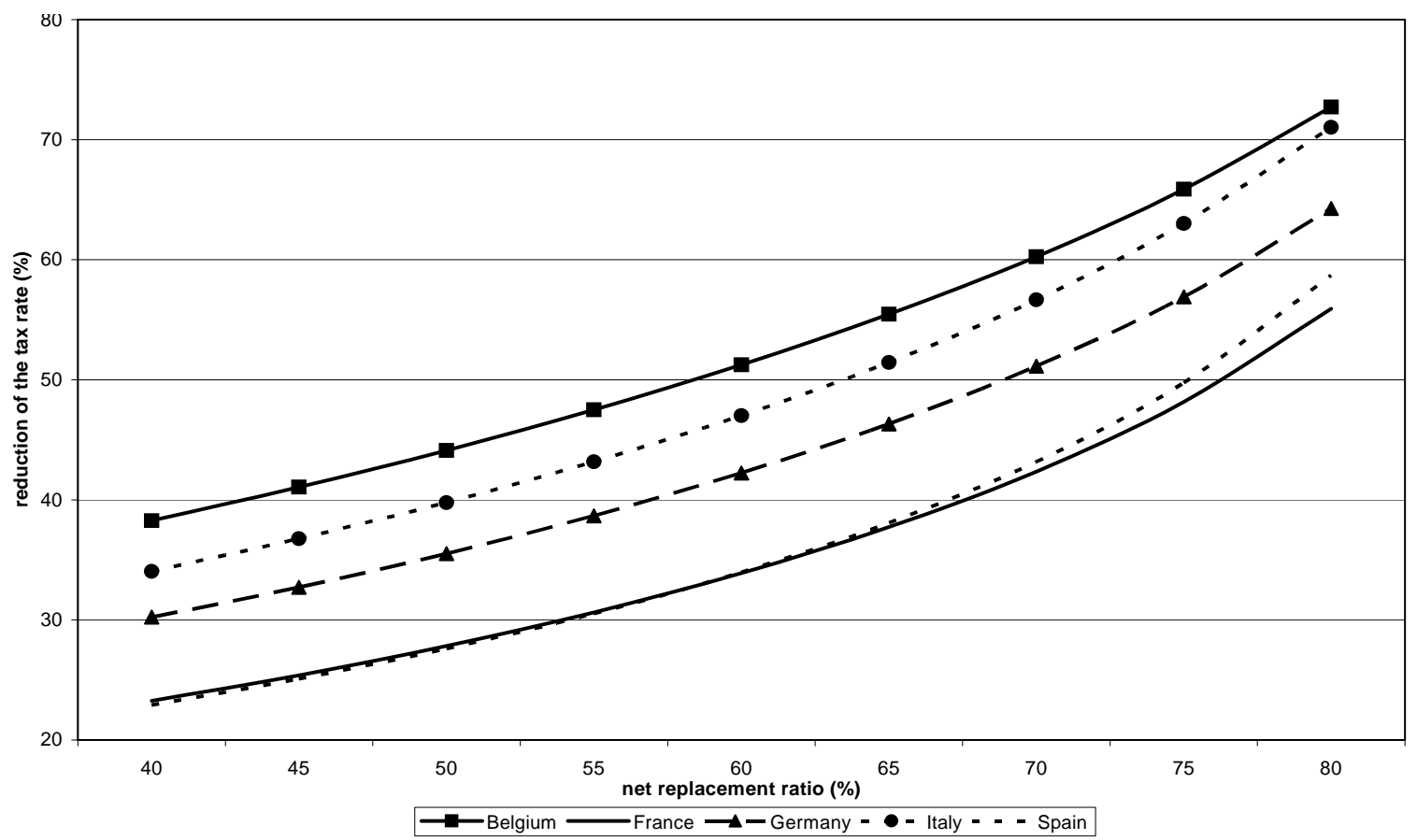

Figure 4: The relation between the net replacement ratio and the percentage reduction in tax rates resulting from a shift to the UA system.

effect and the resulting tax reduction effect. It is for this reason that, as the replacement ratio rises, the switch from the UB to the UA system leads to progressively larger reductions in unemployment and taxes. 


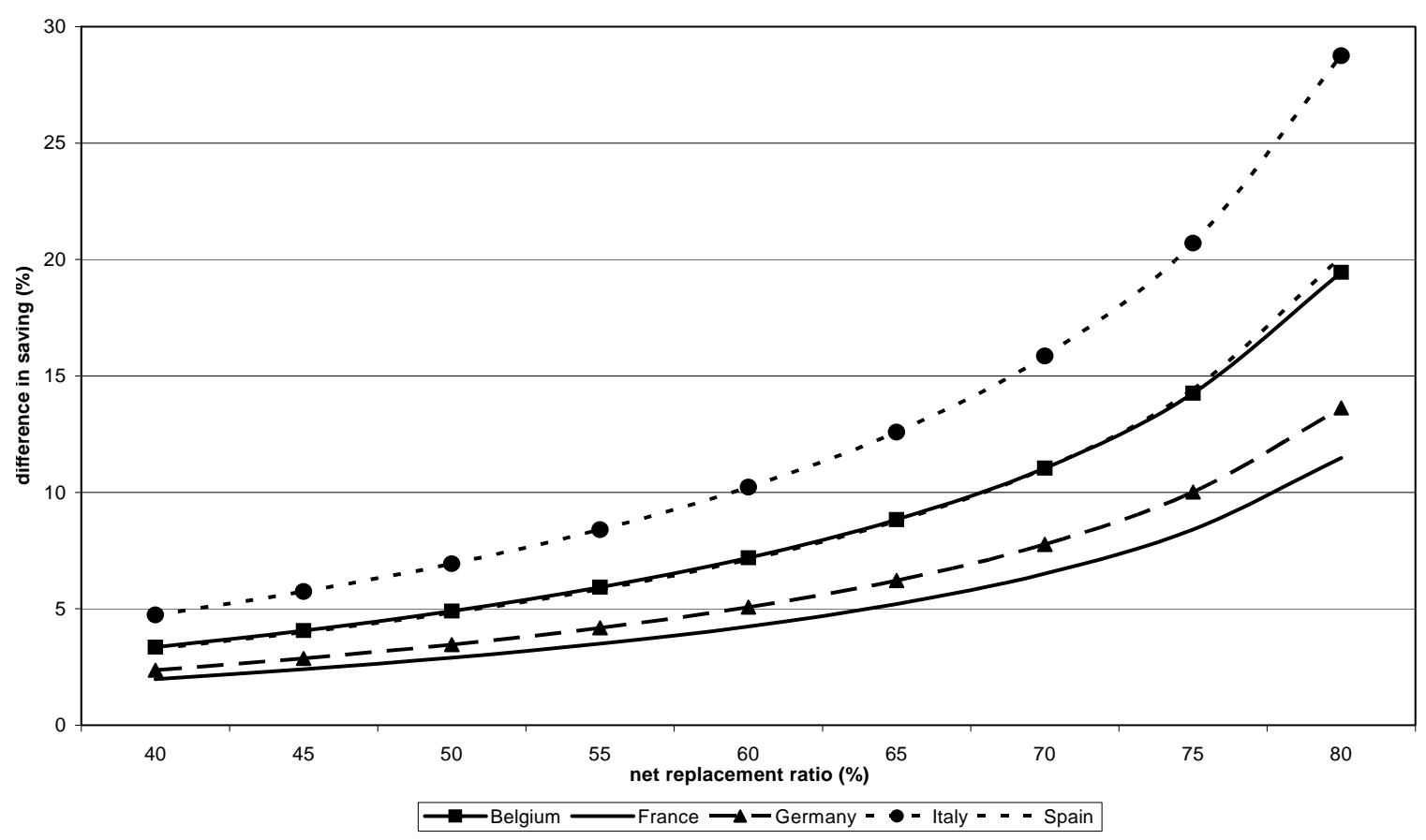

Figure 5: The relation between the net replacement ratio and the percentage difference in saving of young workers between the UA and the UB system.

Fig. 5 shows the difference in saving, in the UA and UB systems, associated with a range of replacement ratios. We compare the total saving of young workers under the two systems, namely, the sum of "voluntary" and "forced" saving under the UA system with saving under the UB system. The vertical axis depicts the percentage difference of young workers' saving between the UA and UB systems. ${ }^{29}$ Under the UB system, workers save less since they do not fully internalise the cost of unemployment. The higher interpersonal reditributions reduce their incentive to save.

\section{Conclusion}

This paper has analysed the implications of moving from the UB to the UA system. To promote understanding of major incentive effects, we have focused on some central characteristics of these systems, assuming that unemployment benefits are financed by payroll taxes. Our simple models are meant to clarify important channels whereby the policy change affects job search and work effort. They also show how the redistribution of income, performed through the UB system, can be accomplished more efficiently through the UA system, permitting significant declines in unemployment rates and improvements in welfare.

In particular, we have shown how UAs permit people to internalise a portion of a significant policy-induced externality: the support of unemployed workers imposes

\footnotetext{
${ }^{29}$ The saving of young workers are calculated as the sum of the weighted savings of employed and unemployed workers, whereby the weights are given by the employment and unemployment rates, respectively.
} 
a tax cost on the employed workers. Under the UA system people finance more of their own unemployment support than under the UB system and thus the externality is reduced. The reason is that every system of unemployment support involves both interpersonal and intrapersonal redistribution. The switch to the UA system reduces the need for the latter through taxes and transfers, since employed people can use their UAs to support themselves should they become unemployed in the future. Lower taxes (uncompensated costs on the employed) and lower transfers (uncompensated benefits to the unemployed) means greater incentives for job search and work effort. The resulting rise in hiring rates and reduction in firing rates leads to a fall in unemployment. This in turn broadens the tax base and shrinks the number of people requiring support, leading to further reductions in tax rates and unemployment benefit expenditures, and so on.

Our calibration exercises suggest that these unemployment reductions could be measurable in Europe's high-unemployment countries. It is important to emphasise that these reductions are achieved without reducing the level of support to the unemployed. Our analysis also shows that switching to the UA system makes unemployment less sensitive to the replacement ratio and that, the higher is this replacement ratio, the greater is the achievable reduction in unemployment. Naturally, in providing a transparent way of describing how the policy change can affect labor market behavior, our models of course make strong simplifying assumptions and thus our results must be interpreted with caution, indicating only general orders of magnitude.

\section{References}

[1] Auer, Peter, Janine Berg and Ibrahim Coulibaly (2004), "Is a stable workforce good for the economy? Insights into the tenure-productivity-employment relationship," Employment Strategy Paper 15/2004, International Labour Office (2004).

[2] Lindbeck, Assar and Dennis J. Snower (1988), The Insider-Outsider Theory of Employment and Unemployment, Cambridge, Mass.: MIT Press.

[3] OECD (2005), Employment Outlook, Paris: OECD.

[4] OECD (2004), Benefit and Wages: OECD Indicators, Paris: OECD.

[5] Orszag, J. Michael and Dennis J. Snower (2000), "The effectiveness of employment vouchers: a simple approach," German Economic Review, No. 4, Vol. 1, pp. 385419 .

[6] Phelps, Edmund (1994), Structural Slumps: the Modern Equilibrium Theory of Unemployment, Interest and Assets, Cambridge, Mass.: Harvard Univ. Press. 


\section{A Appendix}

\section{A.1 Hiring and Firing Rates}

Having assumed that the only way workers perceive they can influence hiring and firing is through the choice of leisure, we provide some microfoundations for such hire and fire rates with a particularily simple model.

There is a large number $M$ of firms, each of which has workers and maximises its present value of profits. Assuming a steady state this is equivalent to maximising one-period profit $\Pi(L, 1)$ :

$$
\begin{aligned}
\Pi(L, 1)= & {\left[\Gamma\left(0, l_{y, n}\right)-w_{y}-d f_{y}\right] L+\left(\Gamma\left(\psi, l_{y, n}\right)-w_{i}\right)\left(1-f_{y}\right) L } \\
& +\left(\Gamma\left(0, l_{o, n}\right)-w_{o}-\varpi\right) \omega N \frac{U_{y}}{M}
\end{aligned}
$$

Here, $\psi$ captures learning by doing in production, $\Gamma$ is productivity which depends on experience and effort, $w_{y}$ is the wage in period $1, w_{o}$ is the wage of those unemployed when young and then become hired, $w_{i}$ is the insider wage, $d$ is the cost of firing a worker, $\varpi$ is the cost of hiring a worker, $l_{y, n}$ is the leisure of the young employed and $l_{o, n}$ of the old employed, $N$ is the number of interviews conducted with each of the young, unemployed workers $\left(U_{y}\right)$ and $\omega$ is the hiring rate at each interview.

Since the purpose of this section is to derive the microfoundations of hire and fire rates, we treat the wages $w_{y}, w_{o}$ and $w_{i}$ in the model as predetermined. We introduce these wages as separate parameters here because they separately influence the hire and fire decisions.

The first order condition for hiring is that, if the firm is hiring, the shadow value of a worker exceeds the marginal hiring cost:

$$
\lambda=\Gamma\left(0, l_{o, n}\right)-w_{o}>\varpi
$$

When a worker comes for interviews at a firm, the firm's hiring decision is based on comparing the estimated shadow values $\lambda-\varepsilon$ (where $\varepsilon$ is a random variable) from hiring the additional employee with marginal training costs $\varpi$. At the interview time, the firm does not know how active the worker has been searching for a job so that its estimates of the shadow value are independent of the amount of search of the employee. The hire rate $\omega$ of the profit-maximising firm then is:

$$
\omega=H(\lambda-\varpi)
$$

where $H$ is the cumulative distribution function of $\varepsilon$.

Workers know the hire rate and have a time endowment of 1 when unemployed and obtaining an interview takes $c$ units of time. Workers who do one interview are hired with a probability $\omega$; if they are not hired (with probability $(1-\omega)$ ), they may proceed to a second interview and be hired with a probability $\omega$. Thus each worker's hiring rate (the total probability of being hired) is: 


$$
h_{y}=\omega \sum_{j=0}^{N-1}(1-\omega)^{j}=1-(1-\omega)^{N}
$$

The hiring rate may now be expressed in terms of the unemployed worker's leisure. Given that the total time endowment (to be split into search and leisure) is 1 , then $N$ interviews take $c N$ units of time. Thus, leisure when unemployed is $(1-c N)$ so that $N=\left(1-l_{y, u}\right) / c$. Hence

$$
h_{y}\left(l_{y, u}\right)=1-(1-\omega)^{\frac{\left(1-l_{y, u}\right)}{c}}
$$

which is decreasing in leisure when unemployed. A linear approximation of eq. 39 is

$$
h_{y}\left(l_{y, u}\right)=\log (1-\omega)\left(\left(l_{y, u}-1\right) / c\right)
$$

which can be rewritten as eq. 18, with hiring propensity $\theta$ and search cost parameter $a$. The hiring rate function formulation implicitly assumes that workers take the wage as given.

The first order condition of the profit maximisation problem eq. 34 for firing is that a worker will be fired if

$$
\Gamma\left(\psi, l_{y, n}\right)-w_{i}<-d
$$

so that a worker is fired when her discounted future contribution to profits falls below minus marginal firing costs $d$. Because the worker is working on projects which may take more than one period, her first period effort will influence her second period productivity. This effect is captured through the random parameter $\psi$ which measures "learning by doing".

Since the learning by doing parameter is random, firing is stochastic and the probability of firing a worker is given by the probability that the following equation is negative:

$$
\Gamma\left(\psi, l_{y, n}\right)-w_{i}-d<0
$$

To simplify analysis, we assume that $\Gamma\left(\psi, l_{y, n}\right)$ is linear:

$$
\Gamma\left(\psi, l_{y, n}\right)=\left(\zeta-l_{y, n}\right) \psi
$$

Hence, the probability of firing the worker is:

$$
f=G\left(\frac{\chi}{\zeta-l_{y, n}}\right)
$$

where $G$ is the cumulative density function of $\psi$ and $\chi=\frac{\beta w-d}{\beta}$. Here, the firing rate is increasing in the level of leisure on the job as well as increasing in the wage $w$. The cumulative density function $G$ can take a variety of forms but we can construct a first order approximation in terms of $l_{y, n}$ about $l_{y, n}=\bar{l}$ :

$$
f_{y}\left(l_{y, n}\right)=\varphi+\phi l_{y, n}
$$


with firm firing propensity $\phi$.

Someone who exhibits full effort and does not shirk at all should not be fired which can be achieved by setting $\varphi=0$, as in eq. 19. The parameters will depend on a number of other parameters including the wage. ${ }^{30}$

\section{A.2 Mean Duration of Job Tenure}

Assume duration independent transition and a steady state. The probability of being fired each period is $f_{y}$. Then the probability of being fired after $t$ periods is

$$
f_{y}\left(1-f_{y}\right)^{t-1}
$$

Thus the mean duration of employment is

$$
f_{y} \sum_{t=1}^{\infty} t\left(1-f_{y}\right)^{t-1}
$$

which can be rewritten as

$$
f_{y} \sum_{t=i}^{\infty} \sum_{i=1}^{\infty}\left(1-f_{y}\right)^{i-1}=\frac{1}{f_{y}}
$$

Hence, if the rate of outflow from employment is $f_{y}$, the mean duration of job tenure is $1 / f_{y}$.

\section{A.3 Total Welfare of the population}

As noted above, the welfare $(W)$ of the population is calculated as the sum of the weighted utility of workers over both labour market states and both generations, whereby the weights are given by their respective shares in the population. As we assume a steady state and each generation having the same size, the absolute size of the population is irrelevant for calculating the percentage changes in welfare. Hence, the respective shares in the population are given by the respective probabilities. Thus:

$$
\begin{aligned}
W= & h_{e}\left(v\left(c_{y, n}, l_{y, n}\right)+\left(1-f_{y}\right) V(i)+f_{y} V(o, s u)\right)+ \\
& \left(1-h_{e}\right)\left(v\left(c_{y, u}, l_{y, u}\right)+\left(1-h_{y}\right) V(o, l u)+h_{y} V(o, s n)\right)
\end{aligned}
$$

\footnotetext{
${ }^{30}$ Another way of justifying this functional form for the firing function is in terms of a shirking model (see Phelps (1994), chapter 15 for details).
} 